\title{
The Relationship Between Sleep Duration and Participation in Home, School, and Community Activities Among School-Aged Children
}

\author{
Chi-Wen Chien*, Pauline Cheung and Chao-Ying Chen \\ Department of Rehabilitation Sciences, The Hong Kong Polytechnic University, Kowloon, Hong Kong
}

\section{OPEN ACCESS}

Edited by:

Amir H. Pakpour,

Qazvin University of Medical

Sciences, Iran

Reviewed by:

Hiromasa Funato,

Toho University, Japan

Michelle Claire Dumoulin Bridi,

Johns Hopkins University,

United States

*Correspondence:

Chi-Wen Chien

will.chien@polyu.edu.hk

Specialty section:

This article was submitted to

Sleep and Circadian Rhythms,

a section of the journal

Frontiers in Neuroscience

Received: 24 May 2019

Accepted: 31 July 2019

Published: 14 August 2019

Citation:

Chien C-W, Cheung P and Chen C-Y (2019) The Relationship

Between Sleep Duration and Participation in Home, School, and Community Activities Among

School-Aged Children.

Front. Neurosci. 13:860. doi: 10.3389/fnins.2019.00860
Sleep duration has important implications for children's participation in daily activities; however, past attempts to examine this relationship has been limited to specific types of physical or educational activities. The present study aimed to investigate the relationship between sleep duration and participation in various daily activities among schoolaged children. A school-based sample of 391 children aged 5-12 years (boys: 52.4\%) participated in this cross-sectional survey. Sleep duration was quantified using parental reports of their children's bedtime and wake-up time on weekdays and weekends. The parent-reported Participation and Environment Measure for Children and Youth was used to measure their children's participation frequency and involvement in 25 home, school, and community activities. The results of hierarchical regression analyses showed that, when the demographic variables were controlled for, weekday sleep duration was positively related to homework involvement and negatively related to the frequency of TV viewing; however, it was unrelated to participation in school and community activities. Conversely, weekend sleep duration was positively related to overall participation in school activities, and participation frequency and involvement in some home and community activities. Furthermore, sleep duration was approximately an hour shorter on weekdays than on weekends. These results suggest that weekend sleep duration has stronger positive implications for children's participation in daily activities than does weekday sleep duration. Interventions aiming to promote children's activity participation may either prolong children's weekend sleep duration or address their shorter weekday sleep duration.

Keywords: participation, sleep, Participation and Environment Measure, PEM-CY, weekday sleep duration, weekend sleep duration

\section{INTRODUCTION}

Adequate sleep plays an important role in healthy child development, and it is also required for the maintenance of physical and mental health. According to the National Sleep Foundation (Hirshkowitz et al., 2015), school-aged children (6-13 years) are recommended to sleep for a duration of 9-11 h per night. However, when compared to earlier times, children in modern societies do not get enough sleep; this is especially true for children who live in Asian and 
North American countries (Matricciani et al., 2012). Insufficient sleep has adverse effects on the cognition, emotional regulation, energy balance, and metabolism of children (St-Onge, 2013; Chaput et al., 2016; Bolinger et al., 2018). These effects have long-term consequences for children's development (Chaput et al., 2016), academic performance (Curcio et al., 2006), health (Smaldone et al., 2007; Medic et al., 2017), and quality of life (Magee et al., 2017). Therefore, understanding the effects of insufficient sleep on children has important implications for the foundation of health guidelines and the development of intervention strategies that can alleviate the adverse effects of insufficient sleep.

Insufficient sleep among school-aged children may lead to low levels of participation in daily activities or a lack of balanced engagement in a variety of daily activities (Ortega et al., 2011; Engle-Friedman, 2014). However, the existing literature on the relationship between sleep duration and activity participation is primarily limited to specific types of physical or educational activities that have been examined across disparate studies ( $\mathrm{Li}$ et al., 2014; Jiang et al., 2015; Khan et al., 2015; Lin et al., 2018). Furthermore, these studies did not examine the relationships between sleep duration and the levels of children's involvement in activities; instead, the participation duration or frequency has been operationalized in most of the studies. The construct of participation has been refined in recent years (Coster et al., 2011b; Kang et al., 2014; Imms et al., 2016b), and it includes two key dimensions: attendance and involvement. Attendance is defined as "being there" reflected by the time spent on or frequency of engaging in activities. Involvement is conceptualized as "the experience of participation" which may include elements of motivation, persistence, social connection, and level of affect (Chien et al., 2014; Imms et al., 2016b). According to this bi-dimensional framework of activity participation, attendance is a necessary but insufficient requirement for high levels of involvement in activities (Imms et al., 2016b). For example, a child may attend soccer practice but may spend a majority of the time passively running around the field and watching for his/her teammates' play the sport. Therefore, it is important to examine the relationship between sleep duration and both dimensions of activity participation, namely, attendance and involvement.

The objective of the present study was to examine the relationship between sleep duration (during weekdays and the weekend) and two dimensions of activity participation (frequency and involvement) among school-aged children. The activities to be examined in this study pertained to a variety of activities in which children took part at home, at school, and in the community.

\section{MATERIALS AND METHODS}

\section{Participants}

Participants were recruited from four mainstream primary schools using convenience sampling. First, invitations to participate in this study were sent to all the schools in Hong Kong. Those schools that were first to accept the invitation in each of the four major geographical regions (i.e., Hong Kong Island, Kowloon, New Territory East, and New Territory West) were included in the study. Children who met the following criteria were included in the study sample: (1) between the ages of 5 and 12 years; (2) no history of diagnoses of diseases or disabilities that might interfere with their ability to participate in activities (i.e., as per parent-reports); and (3) parents can read Chinese.

\section{Procedure}

A cross-sectional school-based survey was conducted between 2017 and 2018. An assessment packet that consisted of printed invitation letters, consent forms, and survey questionnaires were distributed to all the children in the four participating schools. Children were instructed to give the packets to their parents. Parents who were willing to participate in the research study were asked to provide written consent, complete the questionnaires, and return them by post using the prepaid envelopes that were included in the assessment packet. Ethical approval for the present study was granted by the ethical review committee of the Hong Kong Polytechnic University.

\section{Measures}

\section{Activity Participation}

The Participation and Environment Measure for Children and Youth (PEM-CY) (Coster et al., 2011b) is a well-developed parent-reported measure of children's participation in a range of daily activities. The PEM-CY consists of 25 items that measures children's participation in a board range of activities at home (10 items), at school (5 items), and in the community (10 items). In each type of activity, there are a few illustrative examples. For example, in the activity of indoor play and games, the examples include playing with toys, puzzles, or board games, playing kitchen, or dress-up. Parents are asked to think about all of the examples that belong to the activity category when answering following questions. First, parents report how often your child has participated in one or more activities of this type over the last 4 months ( $0=$ never; 7 = daily) and, secondly, how involved your child is when participating in one or two activities of this type that he or she does most often $(1=$ minimally involved; $5=$ very involved). Two types of composite participation scores (namely frequency and involvement) can be generated by averaging the individual item scores that have been recorded for each of the three domains of activities (i.e., home, school, and community settings). The PEM-CY has demonstrated fair to high internal consistency (Cronbach's $\alpha=0.55-0.86$ ) and satisfactory testretest reliability (intraclass correlation coefficients $=0.70-0.84$ ) (Coster et al., 2011a; Chien et al., 2019).

\section{Sleep Duration}

Children's sleep schedules were assessed using a questionnaire that was designed for the purpose of the present study. Parents were asked to indicate the time at which their children typically went to bed at night and woke up in the morning on weekdays and weekends. Sleep duration was calculated as the time that had lapsed between bedtime and wake-up time on weekdays and weekends. The test-retest reliability of this indicator across a 1-month interval was found to be satisfactory (intraclass 
correlation coefficient $=0.79$ for weekdays and 0.81 for weekends) in a subset of 55 children of the study sample.

\section{Demographic Characteristics}

A demographic questionnaire was used to obtain information about children's gender, age, and the presence of any diagnoses/ disabilities, as well as the respondent's relationship with his/her child, age, education, occupation, monthly household income, and district of residence.

\section{Data Analysis}

Means and standard deviations were computed for continuous variables, and percentages were computed for categorical variables. One-way analyses of variance and (independent-samples and paired) $t$-tests were used to examine group differences.

To examine the relationship between sleep duration and activity participation, hierarchical multiple linear regression analyses were conducted. Each of the two composite participation scores for the three domains of activities (i.e., home, school, and community) served as the dependent variable. Since the age, gender, and household income of children have been found to strongly influence activity participation (Brown et al., 2011; Anaby et al., 2014; Imms et al., 2016a), these variables were included as control variables in the first block of the models. In the second block of the models, sleep duration served as the independent variable. Separate analyses were conducted for sleep duration on weekdays and weekends, as different sleep patterns have been reported for these two parts of the week (Wing et al., 2009). The significance level at which the results of these analyses were tested was specified at 0.05 .

Furthermore, hierarchical regression analyses were repeated for each PEM-CY item. For these item-level analyses, Bonferroni corrections (Bland and Altman, 1995) were applied to adjust $p$-values to $0.005,0.010$, and 0.005 for participation in home, school, and community activities, respectively.

In addition, variance inflation factors and residual analyses were performed to search for violations of necessary assumptions (e.g., multicollinearity, homescedasticity, normality, and linearity) for the multiple regression analysis (Tabachnik and Fiddel, 2007). We found that the variation inflation factors of all control and independent variables were found to be less than 3 , indicating that no multicollinearity was present (Pallant, 2007). The residuals of the children's participation in each domain of activities or individual activity appeared to be linear, normally distributed, and homoscedastic when the normality probability plots and scatterplots were examined.

\section{RESULTS}

\section{Demographics, Sleep Duration, and Activity Participation}

A total of 517 parents/caregivers (response rate: 34.9\%) completed the research questionnaires; of these, 396 (76.6\%) were mothers. Further, 82 children had known diagnoses/disabilities and were therefore excluded from the sample. Additionally,
88 children were sibling pairs that represented the same family. Since they tended to coparticipate in activities and have similar sleep schedules, we randomly excluded the data of one child from each family. The final sample included 391 children: 205 boys $(52.4 \%)$ and 186 girls (47.6\%). Their mean age was 8.9 years $(S D=1.8)$, and $272(69.6 \%)$ children's families had monthly incomes that were equal to or higher than the median.

Sleep duration and activity participation as a function of age, gender, and household income are shown in Table 1. The mean sleep duration on a typical weeknight was $9.02 \mathrm{~h}$, and $58.8 \%$ of the children slept for a duration that was lower than the recommended duration for children aged 6-13 years: 9-11 h per night (Hirshkowitz et al., 2015). No significant differences emerged between the groups that differed on gender and household income; however, younger children slept for a longer duration than their older counterparts $(p<0.001)$. In contrast, children slept for a significantly longer duration $(p<0.001)$ on weekend nights $(M=10.01 \mathrm{~h})$ than on weeknights. There were $17.4 \%$ of children who slept for less than $9 \mathrm{~h}$ on weekend nights. Age, gender, and household income did not have a significant effect on weekend sleep duration.

With regard to activity participation, the average frequency scores were 5.53, 4.36, and 2.57 for the home, school, and community activities, respectively. These values indicate that, on average, children engaged in home, school, and community activities few times a week, once a week, and once a month, respectively. The average involvement scores revealed that parents perceived their children's involvement in home $(M=3.84)$, school $(M=3.67)$, and community $(M=2.78)$ activities to be of a moderate level. There were no significant age and gender differences in children's activity participation; however, older children participated more frequently and were more involved in school activities than their younger counterparts ( $p<0.001$; see Table 1). Additionally, children from high-income families participated more frequently in community activities and were more involved in home and community activities than children from low-income families $(p \leq 0.021)$.

\section{Relationships Between Sleep Duration and Participation in Home Activities}

Table 2 shows the relationships that emerged between participation in home activities and sleep duration. With regard to participation frequency, weekday sleep duration was found to be negatively related to watching TV, videos, and DVDs $(\beta=-0.149, p=0.004)$. On the other hand, with regard to participation involvement, weekday sleep duration was positively related to doing homework $(\beta=0.184, p=0.001)$. Furthermore, children who slept for longer duration on weekends tended to be more involved in home activities as a whole $(\beta=0.119, p=0.022)$ and specifically in tasks that were involved in preparing school materials at home $(\beta=0.177, p=0.001)$.

\section{Relationships Between Sleep Duration and Participation in School Activities}

Table 3 shows the relationships that emerged between participation in school activities and sleep duration. Weekday 
TABLE 1 | Sleep duration and activity participation as a function of age, gender, and household income.

\begin{tabular}{|c|c|c|c|c|c|c|c|c|c|c|}
\hline & \multicolumn{4}{|c|}{ Age (in years) } & \multicolumn{3}{|c|}{ Gender } & \multicolumn{3}{|c|}{ Household monthly income } \\
\hline & $\begin{array}{c}5.5-7.5 \\
(n=126)\end{array}$ & $\begin{array}{c}7.6-9.5 \\
(n=114)\end{array}$ & $\begin{array}{l}9.6-12.5 \\
(n=151)\end{array}$ & $p$ & $\begin{array}{c}\text { Boys } \\
(n=205)\end{array}$ & $\begin{array}{c}\text { Girls } \\
(n=186)\end{array}$ & $p$ & $\begin{array}{l}<\text { median } \\
(n=118)\end{array}$ & $\begin{array}{l}\geq \text { median } \\
(n=272)\end{array}$ & $p$ \\
\hline Weekday sleep duration & $9.31(0.68)$ & $8.99(0.69)$ & $8.81(0.77)$ & $<0.001$ & $9.06(7.32)$ & $8.99(0.76)$ & 0.321 & $9.03(0.80)$ & $9.02(0.72)$ & 0.871 \\
\hline Weekend sleep duration & $10.14(0.87)$ & $10.05(1.06)$ & $10.02(1.04)$ & 0.620 & $10.00(1.00)$ & $10.14(0.98)$ & 0.127 & $10.18(1.17)$ & $10.02(0.90)$ & 0.127 \\
\hline \multicolumn{11}{|l|}{ Home participation } \\
\hline Frequency & $5.46(0.69)$ & $5.50(0.64)$ & $5.61(0.64)$ & 0.139 & $5.53(0.64)$ & $5.53(0.69)$ & 0.986 & $5.50(0.74)$ & $5.55(0.63)$ & 0.487 \\
\hline Involvement & $3.89(0.60)$ & $3.76(0.61)$ & $3.85(0.61)$ & 0.274 & $3.85(0.62)$ & $3.83(0.59)$ & 0.754 & $3.73(0.64)$ & $3.89(0.59)$ & 0.021 \\
\hline \multicolumn{11}{|l|}{ School participation } \\
\hline Frequency & $3.97(1.17)$ & $4.21(1.13)$ & $4.83(0.92)$ & $<0.001$ & $4.31(1.17)$ & $4.42(1.09)$ & 0.343 & $4.24(1.17)$ & $4.42(1.11)$ & 0.154 \\
\hline Involvement & $3.40(1.02)$ & $3.63(0.98)$ & $3.92(0.90)$ & $<0.001$ & $3.64(1.03)$ & $3.69(0.94)$ & 0.630 & $3.54(1.05)$ & $3.71(0.96)$ & 0.120 \\
\hline \multicolumn{11}{|c|}{ Community participation } \\
\hline Frequency & $2.68(0.74)$ & $2.45(0.77)$ & $2.57(0.88)$ & 0.093 & $2.60(0.81)$ & $2.54(0.80)$ & 0.509 & $2.33(0.76)$ & $2.66(0.80)$ & $<0.001$ \\
\hline Involvement & $2.89(0.75)$ & $2.66(0.92)$ & $2.78(0.91)$ & 0.146 & $2.79(0.86)$ & $2.77(0.87)$ & 0.823 & $2.52(0.97)$ & $2.87(0.80)$ & 0.001 \\
\hline
\end{tabular}

TABLE 2 | Relationships, indicated by regression coefficients, between sleep duration and participation in home activities.

\begin{tabular}{|c|c|c|c|c|c|c|}
\hline \multirow[b]{2}{*}{ Dependent variable } & \multicolumn{3}{|c|}{ Weekday sleep duration } & \multicolumn{3}{|c|}{ Weekend sleep duration } \\
\hline & $\beta$ & $95 \% \mathrm{Cl}$ & $p$ & $\beta$ & $95 \% \mathrm{Cl}$ & $p$ \\
\hline \multicolumn{7}{|l|}{ Participation frequency } \\
\hline Composite frequency score & 0.025 & $-0.081,0.131$ & 0.640 & 0.069 & $-0.031,0.171$ & 0.176 \\
\hline Computer and video games & -0.023 & $-0.127,0.082$ & 0.673 & -0.053 & $-0.153,0.046$ & 0.291 \\
\hline Indoor play and games & 0.094 & $-0.002,0.191$ & 0.056 & -0.004 & $-0.097,0.088$ & 0.924 \\
\hline Arts, crafts, music, and hobbies & -0.023 & $-0.131,0.085$ & 0.674 & 0.087 & $-0.014,0.189$ & 0.094 \\
\hline Watching TV, videos, and DVDs & -0.149 & $-0.254,-0.042$ & 0.004 & -0.070 & $-0.171,0.031$ & 0.176 \\
\hline Getting together with other people & -0.025 & $-0.132,0.082$ & 0.641 & -0.036 & $-0.138,0.064$ & 0.476 \\
\hline Socializing using technology & -0.017 & $-0.117,0.082$ & 0.725 & 0.029 & $-0.065,0.124$ & 0.543 \\
\hline Household chores & 0.131 & $0.025,0.237$ & 0.015 & 0.104 & $0.003,0.206$ & 0.042 \\
\hline Personal care management & -0.014 & $-0.120,0.093$ & 0.800 & 0.121 & $0.020,0.222$ & 0.019 \\
\hline School preparation (not homework) & 0.046 & $-0.058,0.151$ & 0.383 & 0.078 & $-0.021,0.178$ & 0.124 \\
\hline Homework & 0.019 & $-0.087,0.126$ & 0.721 & 0.095 & $-0.006,0.197$ & 0.065 \\
\hline \multicolumn{7}{|l|}{ Participation involvement } \\
\hline Composite involvement score & 0.072 & $-0.036,0.180$ & 0.191 & 0.119 & $0.017,0.222$ & 0.022 \\
\hline Computer and video games & -0.125 & $-0.230,-0.019$ & 0.020 & -0.064 & $-0.164,0.037$ & 0.216 \\
\hline Indoor play and games & 0.013 & $-0.089,0.117$ & 0.796 & 0.017 & $-0.081,0.115$ & 0.733 \\
\hline Arts, crafts, music, and hobbies & 0.037 & $-0.071,0.144$ & 0.504 & 0.065 & $-0.036,0.168$ & 0.210 \\
\hline Watching TV, videos, and DVDs & -0.105 & $-0.003,0.388$ & 0.053 & 0.014 & $-0.087,0.116$ & 0.782 \\
\hline Getting together with other people & 0.089 & $-0.017,0.196$ & 0.100 & 0.061 & $-0.040,0.163$ & 0.236 \\
\hline Socializing using technology & -0.005 & $-0.109,0.099$ & 0.921 & 0.038 & $-0.060,0.137$ & 0.449 \\
\hline Household chores & 0.053 & $-0.055,0.161$ & 0.336 & 0.100 & $-0.001,0.203$ & 0.053 \\
\hline Personal care management & 0.055 & $-0.053,0.163$ & 0.320 & 0.082 & $-0.021,0.184$ & 0.119 \\
\hline School preparation (not homework) & 0.122 & $0.014,0.229$ & 0.026 & 0.177 & $0.007,0.279$ & 0.001 \\
\hline Homework & 0.184 & $0.077,0.291$ & 0.001 & 0.119 & $-0.017,0.222$ & 0.022 \\
\hline
\end{tabular}

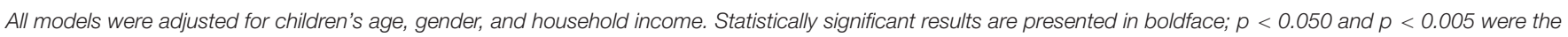
levels of significance that were used to test the composite scores and individual item scores, respectively.

sleep duration was unrelated to participation frequency and involvement in school activities. In contrast, weekend sleep duration was positively related to both the frequency of participation $(\beta=0.109, p=0.024)$ and involvement $(\beta=0.115$, $p=0.023)$ in school activities (i.e., composite scale score).
Specifically, children who slept for longer duration on weekends tended to participate more frequently $(\beta=0.154, p=0.002)$ and be more involved $(\beta=0.152, p=0.002)$ in prosocial activities at school by playing roles such as a class leader, discipline leader, or student mentor. 
TABLE 3 | Relationships, indicated by regression coefficients, between sleep duration and participation in school activities.

\begin{tabular}{|c|c|c|c|c|c|c|}
\hline \multirow[b]{2}{*}{ Dependent variable } & \multicolumn{3}{|c|}{ Weekday sleep duration } & \multicolumn{3}{|c|}{ Weekend sleep duration } \\
\hline & $\beta$ & $95 \% \mathrm{Cl}$ & $p$ & $\beta$ & $95 \% \mathrm{Cl}$ & $p$ \\
\hline Composite frequency score & 0.036 & $-0.064,0.136$ & 0.479 & 0.109 & $0.014,0.203$ & 0.024 \\
\hline Classroom activities & 0.073 & $-0.033,0.180$ & 0.176 & 0.026 & $-0.076,0.128$ & 0.613 \\
\hline Field trips and school events & 0.122 & $0.016,0.228$ & 0.023 & 0.046 & $-0.056,0.147$ & 0.375 \\
\hline Special roles at school & $<0.001$ & $-0.102,0.103$ & 0.999 & 0.154 & $0.057,0.251$ & 0.002 \\
\hline \multicolumn{7}{|l|}{ Participation involvement } \\
\hline Composite involvement score & -0.013 & $-0.118,0.091$ & 0.804 & 0.115 & $0.015,0.214$ & 0.023 \\
\hline Classroom activities & 0.054 & $-0.053,0.163$ & 0.321 & 0.121 & $0.017,0.223$ & 0.021 \\
\hline Field trips and school events & -0.049 & $-0.157,0.059$ & 0.370 & 0.044 & $-0.058,0.147$ & 0.393 \\
\hline
\end{tabular}

All models were adjusted for children's age, gender, and household income. Statistically significant results are presented in boldface; $p<0.050$ and $p<0.010$ were the levels of significance that were used to test the composite scores and individual item scores, respectively.

TABLE 4 | Relationships, indicated by regression coefficients, between sleep duration and participation in community activities.

\begin{tabular}{|c|c|c|c|c|c|c|}
\hline \multirow[b]{2}{*}{ Dependent variable } & \multicolumn{3}{|c|}{ Weekday sleep duration } & \multicolumn{3}{|c|}{ Weekend sleep duration } \\
\hline & $\beta$ & $95 \% \mathrm{Cl}$ & $p$ & $\beta$ & $95 \% \mathrm{Cl}$ & $p$ \\
\hline \multicolumn{7}{|l|}{ Participation frequency } \\
\hline Composite frequency score & 0.084 & $-0.024,0.207$ & 0.122 & 0.099 & $-0.002,0.201$ & 0.057 \\
\hline Neighborhood outings & 0.021 & $-0.008,0.124$ & 0.690 & 0.051 & $-0.046,0.150$ & 0.299 \\
\hline Community events & -0.041 & $-0.150,0.067$ & 0.451 & 0.090 & $-0.012,0.193$ & 0.083 \\
\hline Classes and lessons (not school-sponsored) & -0.001 & $-0.106,0.103$ & 0.983 & 0.149 & $0.050,0.247$ & 0.003 \\
\hline Organizations, groups, clubs, and volunteer or leadership activities & 0.003 & $-0.103,0.111$ & 0.947 & -0.003 & $-0.105,0.098$ & 0.950 \\
\hline Religious or spiritual gatherings and activities & 0.088 & $-0.020,0.196$ & 0.109 & -0.015 & $-0.118,0.088$ & 0.775 \\
\hline Getting together with other children in the community & 0.082 & $-0.024,0.187$ & 0.128 & 0.029 & $-0.071,0.129$ & 0.571 \\
\hline Working for pay & 0.101 & $-0.007,0.210$ & 0.069 & -0.021 & $-0.125,0.083$ & 0.687 \\
\hline Community events & -0.067 & $-0.177,0.043$ & 0.234 & 0.052 & $-0.052,0.157$ & 0.327 \\
\hline Organized physical activities & 0.120 & $0.011,0.228$ & 0.031 & 0.089 & $-0.014,0.192$ & 0.090 \\
\hline Unstructured physical activities & 0.058 & $-0.049,0.167$ & 0.288 & -0.018 & $-0.121,0.084$ & 0.726 \\
\hline Classes and lessons (not school-sponsored) & 0.038 & $-0.069,0.145$ & 0.482 & 0.077 & $-0.024,0.179$ & 0.135 \\
\hline Organizations, groups, clubs, and volunteer or leadership activities & -0.009 & $-0.119,0.100$ & 0.863 & -0.004 & $-0.108,0.100$ & 0.935 \\
\hline Religious or spiritual gatherings and activities & 0.009 & $-0.019,0.203$ & 0.103 & -0.053 & $-0.159,0.053$ & 0.323 \\
\hline Getting together with other children in the community & -0.016 & $-0.124,0.092$ & 0.775 & 0.016 & $-0.087,0.119$ & 0.759 \\
\hline Working for pay & 0.079 & $-0.030,0.189$ & 0.157 & -0.004 & $-0.109,0.101$ & 0.936 \\
\hline Overnight visits or trips & 0.045 & $-0.065,0.157$ & 0.421 & 0.064 & $-0.040,0.170$ & 0.228 \\
\hline
\end{tabular}

All models were adjusted for children's age, gender, and household income. Statistically significant results are presented in boldface; $p<0.050$ and $p<0.005$ were the levels of significance that were used to test the composite scores and individual item scores, respectively.

\section{Relationships Between Sleep Duration and Participation in Community Activities}

Table 4 shows the relationships that emerged between participation in community activities and sleep duration.
Weekday sleep duration was unrelated to both participation frequency and involvement in community activities. Similarly, weekend sleep duration was also unrelated to the level of involvement in community activities; however, it was positively 
related to the frequency of participation in community-based classes and lessons $(\beta=0.149, p=0.003)$.

\section{DISCUSSION}

Activity participation offers children opportunities to learn new skills, develop physical abilities, make friends, and establish their sense of purpose (Law, 2002; Hoogsteen and Woodgate, 2010; Chien and Rodger, 2011), and it has been recognized as an important contributor to health and quality of life (Colver, 2009; Holder et al., 2009; Berg et al., 2018). To our knowledge, the present study is the first to investigate the relationships between sleep duration and the frequency and involvement with which school-aged children participate in a wide range of activities. Overall, our results show that children slept for longer duration of time on weekend nights than on weeknights. Furthermore, longer weekend sleep duration was related to a higher frequency and greater involvement in home, school, and community activities. However, weekday sleep duration was negatively related to the frequency of watching TV and positively related to the involvement in doing homework; it was unrelated to school and community activities. These findings highlight the influence of weekday and weekend sleep duration on children's different activity participation patterns.

Previous studies have reported that children sleeping less were likely to have a sedentary and inactive lifestyle coupled with more time spent on watching TV and homework completion (Li et al., 2014; Jiang et al., 2015; Lin et al., 2018). Reciprocally, more time spent on TV viewing and finishing homework may delay children's bedtime and shorten their sleep duration (Li et al., 2007; Calamaro et al., 2009). Similar relationships between weekday sleep duration and the frequency of TV viewing was also observed in the present study, although the crosssectional research design of this study did not allow us to determinate the direction of the relationships. However, with regard to homework, we found that short sleep duration was associated with low involvement but not high frequency. Thus, we speculated that short sleep duration might lead to tiredness or poor concentration during the daytime (O’Brien, 2009; St-Onge, 2013; Bolinger et al., 2018). This in turn might cause children to be less involved in homework activities and subsequently prolong the time that is required to finish their homework. Because previous studies have focused exclusively on the time that was spent on homework (Li et al., 2014; Jiang et al., 2015), the present findings on the relationship between sleep duration and involvement in doing one's homework make a noteworthy contribution to the existing literature.

Interestingly, we did not find a relationship between weekday sleep duration and participation in school or community activities. However, it is noted that we controlled for age, gender, and household income when examining the relationships between sleep duration and activity participation. Significant age differences emerged for school participation; similarly, significant differences in participation in community activities emerged between the groups that differed in household income (see Table 1). It is thus possible that the impact of short sleep duration on participation in school and community activities might be largely explained by the demographic variables. To test this possibility, we conducted the additional regression analyses by entering weekday sleep duration first and demographic variables subsequently. Significant relationships between weekday sleep duration and participation in some school and community activities attenuated when the demographic variables were entered into the models (results are not shown). In particular, children's age and/or household income became the strongest factors of nearly half the number of school and community activities in those models. This result is in accordance with past findings that children's activity participation involves a dynamic interdependence between personal, familial, and environmental factors (Law et al., 2007; Verdonschot et al., 2009; Anaby et al., 2014; Chien et al., 2017; Cho et al., 2018). Accordingly, weekday sleep duration may play a less important role than other personal and environmental factors in children's participation in school and community activities.

In contradistinction to the findings that emerged for weekday sleep duration, weekend sleep duration was positively related to participation in not only home activities but also in school and community activities. One possible explanation for the relationships that emerged for weekend sleep duration but not for weekday sleep duration may pertain to the benefits of weekend sleep extension (also known as weekend catch-up sleep). In the present study, the average duration of sleep was approximately an hour $(1.04 \mathrm{~h})$ longer on weekends than on weekdays. Particularly, $94.3 \%$ of 230 children who slept for shorter duration (i.e., $\leq 9 \mathrm{~h}$ ) during the week were found to sleep, on average, $1.38 \mathrm{~h}$ $(S D=0.97)$ longer on weekends. Similarly, the longer duration of sleep on weekends than on weekdays $(M=0.55 ; S D=1.08)$ was also found in $67.7 \%$ of 161 children who slept for more than $9 \mathrm{~h}$ during the week. This trend is consistent with past findings that elementary-school children $(N=5159)$ slept for longer duration on weekends to compensate for the insufficient sleep that they got throughout the week (Wing et al., 2009). Studies have shown that weekend catch-up sleep can restore the cognitive impairments that were caused by sleep restrictions that one got on weeknights (Kuula et al., 2015; Agostini et al., 2017). Children who slept for longer duration on weekends might have better attention and concentration and, therefore, might demonstrate a higher frequency of participation or greater involvement in activities such as preparing school materials at home, playing special roles at school, and attending extracurricular classes in the community. In the short term, weekend catch-up sleep may serve as a buffer against insufficient sleep on weekdays and may enhance participation in daily activities. Nonetheless, oversleeping on weekends may not be a suitable long-term solution. Specifically, a growing body of research suggests that children who sleep for longer duration on weekends tend to skip breakfast, develop irregular cortisol circadian rhythm, and have impaired executive functions; these in turn result in poor academic performance, depression, and weight gain (overweight/obesity) (Kuula et al., 2015; Becker et al., 2017; Sun et al., 2019).

There are several limitations that must be considered when the findings of the present study are interpreted. First, the present study used a well-developed and validated parent-reported 
questionnaire (i.e., the PEM-CY) to assess children's activity participation. However, parents' interpretations of their child's participation may differ from those of the children. Furthermore, the PEM-CY did not obtain parents' report on their children's participation duration for each activity, and it is possible that children's sleep duration might be affected more by the activities in which they do not participate often but spend many hours each time they participate. Second, children's sleep duration was defined as the span of time between bedtime and wake-up time, both of which were reported by parents; therefore, the sleep duration that was computed may be overestimated. In addition, we did not collect either information on daytime naps or sleep quality in this study. Future studies that use objective actigraphic measures of sleep duration and comprehensive measures of sleep parameters are needed. Third, factors such as commuting time, seasonal effects, and environmental barriers that may impact children's activity participation and sleep behaviors were not taken into account in the present study. Future studies to include these factors may provide us a more comprehensive picture to address the concerns proposed in the present study. Finally, the present study entailed a cross-sectional survey design and, therefore, the causality of the observed relationships must be tested in future prospective and experimental studies.

\section{CONCLUSION}

Weekday sleep duration was associated with school-aged children's participation in some home activities but not school or community activities. In contrast, weekend sleep duration was associated with participation frequency and involvement in home, school, and community activities. Our findings also showed that the duration of sleep was approximately an hour longer on weekends than on weekdays, thereby indicating the phenomenon of weekend catch-up sleep that is common among school-aged children. Therefore, interventions that aim to promote children's participation in daily activities may need to incorporate strategies that ensure the adequate sleep children

\section{REFERENCES}

Agostini, A., Carskadon, M. A., Dorrian, J., Coussens, S., and Short, M. A. (2017). An experimental study of adolescent sleep restriction during a simulated school week: changes in phase, sleep staging, performance and sleepiness. J. Sleep Res. 26, 227-235. doi: 10.1111/jsr.12473

Anaby, D., Law, M., Coster, W., Bedell, G., Khetani, M., Avery, L., et al. (2014). The mediating role of the environment in explaining participation of children and youth with and without disabilities across home, school, and community. Arch. Phys. Med. Rehabil. 95, 908-917. doi: 10.1016/j.apmr.2014. 01.005

Becker, S. P., Sidol, C. A., Van Dyk, T. R., Epstein, J. N., and Beebe, D. W. (2017). Intraindividual variability of sleep/wake patterns in relation to child and adolescent functioning: a systematic review. Sleep Med. Rev. 34, 94-121. doi: 10.1016/j.smrv.2016.07.004

Berg, K. L., Medrano, J., Acharya, K., Lynch, A., and Msall, M. E. (2018). Health impact of participation for vulnerable youth with disabilities. Am. J. Occup. Ther. 72, 7205195040p1-7205195040p9. doi: 10.5014/ajot.2018.023622

Bland, J. M., and Altman, D. G. (1995). Multiple significance tests: the Bonferroni method. BMJ 310:170. doi: 10.1136/bmj.310.6973.170 get on both weeknights and weekend nights. Increasing the awareness of the associations between sleep duration and activity participation could be also the focus of future health promotion programs for school-aged children and their parents.

\section{DATA AVAILABILITY}

The raw data supporting the conclusions of this manuscript will be made available by the authors, without undue reservation, to any qualified researcher.

\section{AUTHOR CONTRIBUTIONS}

C-WC conceived and designed the study, supervised the data collection, carried out the initial analyses, and drafted the initial manuscript. PC reviewed the relevant literature, carried out parts of the analyses, and critically reviewed the manuscript for important intellectual content. C-YC co-designed the study, reviewed the relevant literature, and critically reviewed the manuscript for important intellectual content. All authors approved the final manuscript as submitted and agreed to be accountable for all aspects of the work.

\section{FUNDING}

This work was funded by the New Staff Start-up Fund (Grant Number: 1-ZE4E) and the Central Research Fund (Grant Numbers: G-YBPC and G-YBYP) from The Hong Kong Polytechnic University.

\section{ACKNOWLEDGMENTS}

We thank Ms. Ka-Yan Leung for her assistance in data collection and all schools involved in this study.

Bolinger, E., Born, J., and Zinke, K. (2018). Sleep divergently affects cognitive and automatic emotional response in children. Neuropsychologia 117, 84-91. doi: 10.1016/j.neuropsychologia.2018.05.015

Brown, T., O’Keefe, S., and Stagnitti, K. (2011). Activity preferences and participation of school-age children living in urban and rural environments. Occup. Ther. Health Care. 25, 225-239. doi: 10.3109/07380577.2011.589889

Calamaro, C. J., Mason, T. B., and Ratcliffe, S. J. (2009). Adolescents living the 24/7 lifestyle: effects of caffeine and technology on sleep duration and daytime functioning. Pediatrics 123, 1005-1010. doi: 10.1542/peds.2008-3641

Chaput, J. P., Gray, C. E., Poitras, V. J., Carson, V., Gruber, R., Olds, T., et al. (2016). Systematic review of the relationships between sleep duration and health indicators in school-aged children and youth. Appl. Physiol. Nutr. Metab. 41, 266-282. doi: 10.1139/apnm-2015-0627

Chien, C. W., Li-Tsang, C. W. P., Cheung, P. P. P., Leung, K. Y., and Lin, C. Y. (2019). Development and psychometric evaluation of the Chinese version of the participation and environment measure for children and youth. Disabil. Rehabil. doi: 10.1080/09638288.09632018.01553210 [Epub ahead of print].

Chien, C. W., and Rodger, S. (2011). Applying a new participation definition in paediatric populations: issues and challenges. Arch. Phys. Med. Rehabil. 92:2096. doi: 10.1016/j.apmr.2011.08.033 
Chien, C. W., Rodger, S., and Copley, J. (2017). Parent-reported participation in children with moderate-to-severe developmental disabilities: preliminary analysis of associated factors using the ICF. Int. J. Disabil. Dev. Edu. 64, 483-496. doi: 10.1080/1034912x.2017.1290221

Chien, C. W., Rodger, S., Copley, J., and Skorka, K. (2014). Comparative content review of children's participation measures using the international classification of functioning, disability and health-children and youth. Arch. Phys. Med. Rehabil. 95, 141-152. doi: 10.1016/j.apmr.2013. 06.027

Cho, M., Rodger, S., Copley, J., and Chien, C. W. (2018). Participation in school-related activities that require hand use for children with and without developmental disabilities. J. Intellect. Disabil. Res. 62, 262-268. doi: 10.1111/ jir.12459

Colver, A. (2009). Quality of life and participation. Dev. Med. Child. Neurol. 51, 656-659.

Coster, W., Bedell, G., Law, M., Khetani, M. A., Teplicky, R., Liljenquist, K., et al. (2011a). Psychometric evaluation of the participation and environment measure for children and youth. Dev. Med. Child. Neurol. 53, 1030-1037. doi: 10.1111/j.1469-8749.2011.04094.x

Coster, W., Law, M., Bedell, G., Khetani, M., Cousins, M., and Teplicky, R. (2011b). Development of the participation and environment measure for children and youth: conceptual basis. Disabil. Rehabil. 34, 238-246. doi: 10.3109/09638288. 2011.603017

Curcio, G., Ferrara, M., and De Gennaro, L. (2006). Sleep loss, learning capacity and academic performance. Sleep Med. Rev. 10, 323-337. doi: 10.1016/j.smrv. 2005.11.001

Engle-Friedman, M. (2014). The effects of sleep loss on capacity and effort. Sleep Sci. 7, 213-224. doi: 10.1016/j.slsci.2014.11.001

Hirshkowitz, M., Whiton, K., Albert, S. M., Alessi, C., Bruni, O., DonCarlos, L., et al. (2015). National sleep foundation's sleep time duration recommendations: methodology and results summary. Sleep Health. 1, 40-43. doi: 10.1016/j.sleh. 2014.12.010

Holder, M. D., Coleman, B., and Sehn, Z. L. (2009). The contribution of active and passive leisure to children's well-being. J. Health Psychol. 14, 378-386. doi: $10.1177 / 1359105308101676$

Hoogsteen, L., and Woodgate, R. L. (2010). Can I play? A concept analysis of participation in children with disabilities. Phys. Occup. Ther. Pediatr. 30, 325-339. doi: 10.3109/01942638.2010.481661

Imms, C., Froude, E., Adair, B., and Shields, N. (2016a). A descriptive study of the participation of children and adolescents in activities outside school. BMC Pediatr. 16:84. doi: 10.1186/s12887-016-0623-9

Imms, C., Granlund, M., Wilson, P. H., Steenbergen, B., Rosenbaum, P. L., and Gordon, A. M. (2016b). Participation, both a means and an end: a conceptual analysis of processes and outcomes in childhood disability. Dev. Med. Child. Neurol. 59, 16-25. doi: 10.1111/dmcn.13237

Jiang, X., Hardy, L. L., Baur, L. A., Ding, D., Wang, L., and Shi, H. (2015). Sleep duration, schedule and quality among urban Chinese children and adolescents: associations with routine after-school activities. PLoS One 10:e0115326. doi: 10.1371/journal.pone.0115326

Kang, L. J., Palisano, R. J., King, G. A., and Chiarello, L. A. (2014). A multidimensional model of optimal participation of children with physical disabilities. Disabil. Rehabil. 36, 1735-1741. doi: 10.3109/09638288.2013. 863392

Khan, M. K., Chu, Y. L., Kirk, S. F., and Veugelers, P. J. (2015). Are sleep duration and sleep quality associated with diet quality, physical activity, and body weight status? A population-based study of Canadian children. Can. J. Public Health. 106, 277-282. doi: 10.17269/cjph.106.4892

Kuula, L., Pesonen, A. K., Martikainen, S., Kajantie, E., Lahti, J., Strandberg, T., et al. (2015). Poor sleep and neurocognitive function in early adolescence. Sleep Med. 16, 1207-1212. doi: 10.1016/j.sleep.2015.06.017

Law, M. (2002). Participation in the occupations of everyday life. Am. J. Occup. Ther. 56, 640-649. doi: 10.5014/ajot.56.6.640
Law, M., Petrenchik, T., King, G., and Hurley, P. (2007). Perceived environmental barriers to recreational, community, and school participation for children and youth with physical disabilities. Arch. Phys. Med. Rehabil. 88, 1636-1642. doi: 10.1016/j.apmr.2007.07.035

Li, S., Jin, X., Wu, S., Jiang, F., Yan, C., and Shen, X. (2007). The impact of media use on sleep patterns and sleep disorders among school-aged children in China. Sleep 30, 361-367. doi: 10.1093/sleep/30.3.361

Li, S., Yang, Q., Chen, Z., Jin, X., Jiang, F., and Shen, X. (2014). Homework schedule: an important factor associated with shorter sleep duration among Chinese school-aged children. Behav. Sleep Med. 12, 389-397. doi: 10.1080/15402002. 2013.821654

Lin, Y., Tremblay, M. S., Katzmarzyk, P. T., Fogelholm, M., Hu, G., Lambert, E. V., et al. (2018). Temporal and bi-directional associations between sleep duration and physical activity/sedentary time in children: an international comparison. Prev. Med. 111, 436-441. doi: 10.1016/j.ypmed.2017.12.006

Magee, C. A., Robinson, L., and Keane, C. (2017). Sleep quality subtypes predict health-related quality of life in children. Sleep Med. 35, 67-73. doi: 10.1016/j. sleep.2017.04.007

Matricciani, L., Olds, T., and Petkov, J. (2012). In search of lost sleep: secular trends in the sleep time of school-aged children and adolescents. Sleep Med. Rev. 16, 203-211. doi: 10.1016/j.smrv.2011.03.005

Medic, G., Wille, M., and Hemels, M. E. (2017). Short- and long-term health consequences of sleep disruption. Nat. Sci. Sleep. 9, 151-161. doi: 10.2147/NSS. S134864

O'Brien, L. M. (2009). The neurocognitive effects of sleep disruption in children and adolescents. Child Adolesc. Psychiatr. Clin. N. Am. 18, 813-823. doi: 10. 1016/j.chc.2009.04.008

Ortega, F. B., Ruiz, J. R., Labayen, I., Kwak, L., Harro, J., Oja, L., et al. (2011). Sleep duration and activity levels in estonian and Swedish children and adolescents. Eur. J. Appl. Physiol. 111, 2615-2623. doi: 10.1007/s00421-011-1883-6

Pallant, J. F. (2007). SPSS Survival Manual: A Step-by-Step Guide to Data Analysis With SPSS, 3rd Edn. Crows Nest, NSW: Allen \& Unwin.

Smaldone, A., Honig, J. C., and Byrne, M. W. (2007). Sleepless in America: inadequate sleep and relationships to health and well-being of our nation's children. Pediatrics 119(Suppl. 1), 29-37.

St-Onge, M. P. (2013). The role of sleep duration in the regulation of energy balance: effects on energy intakes and expenditure. J. Clin. Sleep Med. 9, 73-80. doi: $10.5664 / j \mathrm{csm} .2348$

Sun, W., Ling, J., Zhu, X., Lee, T. M., and Li, S. X. (2019). Associations of weekdayto-weekend sleep differences with academic performance and health-related outcomes in school-age children and youths. Sleep Med. Rev. 46, 27-53. doi: 10.1016/j.smrv.2019.04.003

Tabachnik, B. G., and Fiddel, L. S. (2007). Using Multivariate Statistics, 5th Edn. Boston, NY: Allyn and Bacon.

Verdonschot, M. M., de Witte, L. P., Reichrath, E., Buntinx, W. H., and Curfs, L. M. (2009). Impact of environmental factors on community participation of persons with an intellectual disability: a systematic review. J. Intellect. Disabil. Res. 53, 54-64. doi: 10.1111/j.1365-2788.2008.01128.x

Wing, Y. K., Li, S. X., Li, A. M., Zhang, J., and Kong, A. P. (2009). The effect of weekend and holiday sleep compensation on childhood overweight and obesity. Pediatrics 124, 994-1000. doi: 10.1542/peds.2008-3602

Conflict of Interest Statement: The authors declare that the research was conducted in the absence of any commercial or financial relationships that could be construed as a potential conflict of interest.

Copyright $\odot 2019$ Chien, Cheung and Chen. This is an open-access article distributed under the terms of the Creative Commons Attribution License (CC BY). The use, distribution or reproduction in other forums is permitted, provided the original author(s) and the copyright owner(s) are credited and that the original publication in this journal is cited, in accordance with accepted academic practice. No use, distribution or reproduction is permitted which does not comply with these terms. 